\title{
Alçamento vocálico das vogais médias pretônicas iniciais na variedade do noroeste paulista
}

DOI: http://dx.doi.org/10.21165/el.v48i2.2355

\section{Márcia Cristina do Carmo'}

\section{Resumo}

Este trabalho analisa o alçamento das vogais médias pretônicas na variedade do noroeste do estado de São Paulo. Avança em relação aos estudos de Silveira (2008), Carmo (2009, 2013, 2014) e Carmo e Tenani (2013), por discorrer especificamente sobre o comportamento dessas vogais em contexto de início de vocábulo (cf. BISOL, 1981), como em [e]mergência [i]mergência e [o]portunidade [u]portunidade. Como arcabouço teórico, segue-se a Teoria da Variação e Mudança Linguística (LABOV, 2008 [1972]). O córpus desta pesquisa engloba 38 inquéritos do banco de dados IBORUNA (Projeto ALIP - IBILCE/UNESP - FAPESP 03/08058-6). Com a utilização do pacote estatístico Goldvarb X, observam-se comportamentos diferenciados das pretônicas /e/ e /o/ iniciais em relação ao alçamento, com taxas de 76,8\% e 1,7\%, respectivamente. Ademais, evidenciam-se resultados distintos aos de vogais médias pretônicas em contexto medial na mesma variedade (CARMO, 2013, 2014; CARMO; TENANI, 2013).

Palavras-chave: variação fonológica; alçamento vocálico; vogais médias pretônicas iniciais.

1 Universidade Estadual de Ponta Grossa (UEPG), Ponta Grossa, Paraná, Brasil; mccarmo@uepg.br; https://orcid.org/0000-0003-0546-7622 


\title{
Vowel raising of initial pretonic mid-vowels in the variety of paulista Northwest
}

\begin{abstract}
This work analyses the vowel raising of pretonic mid-vowels in the Northwest of São Paulo State variety. It advances in relation to the works of Silveira (2008), Carmo (2009, 2013, 2014) and Carmo and Tenani (2013) since it describes specifically the behaviour of these vowels in word-initial context (BISOL, 1981), e.g. [e]mergência [i]mergência ('emergency') and [o]portunidade $\sim$ [u]portunidade ('opportunity'). This work follows the theoretical background of the Theory of Linguistic Variation and Change (LABOV, 2008 [1972]). The corpus of this research is formed of 38 interviews taken from IBORUNA database (ALIP project - IBILCE/UNESP - FAPESP 03/08058-6). With the utilisation of Goldvarb X statistical package, different behaviours of initial pretonic /e/ and /o/ concerning vowel raising are observed, with rates of $76.8 \%$ and $1.7 \%$, respectively. Furthermore, this work evinces different results from the ones with respect to word-medial pretonic mid-vowels in the same variety (CARMO, 2013, 2014; CARMO; TENANI, 2013).
\end{abstract}

Keywords: phonological variation; vowel raising; word-initial pretonic mid-vowels.

\section{Introdução}

O presente trabalho ${ }^{2}$ analisa o comportamento fonético-fonológico das vogais médias pretônicas em início absoluto de vocábulo na variedade do noroeste paulista, região em que está situado o município de São José do Rio Preto (SP). Essas vogais estão sujeitas ao fenômeno variável denominado alçamento vocálico, por meio do qual as vogais médias /e/ e /o/ passam a ser realizadas, respectivamente, como [i] e [u], como em [i]nfermeira e [u]bedecia.

Há mais de três décadas, muitos trabalhos vêm sendo realizados acerca das vogais médias pretônicas em diferentes variedades do Português Brasileiro (doravante, PB). Isso se justifica pela importância desses segmentos para a caracterização fonológica da Língua Portuguesa, já que a variação entre diferentes segmentos vocálicos - como [e i] e [o u] - em contexto de sílaba pretônica revela variação dialetal.

No que diz respeito ao estado de São Paulo, entretanto, os estudos que abordam essa temática são poucos. Para a variedade do noroeste paulista, Silveira (2008) discorre sobre o alçamento das vogais médias pretônicas em nomes, enquanto Carmo (2009) trata desse mesmo fenômeno em verbos. Carmo $(2013,2014)$ e Carmo e Tenani $(2013)$, por

2 Este artigo apresenta resultados de um estágio pós-doutoral realizado na University College London (UCL/Reino Unido) e financiado pela Coordenação de Aperfeiçoamento de Pessoal de Nível Superior (CAPES - Proc. 10895-13-2). 
sua vez, avançam em relação aos trabalhos anteriores analisando, concomitantemente, vogais médias pretônicas em nomes e em verbos e refinam a investigação do fenômeno, por meio: (i) da utilização de um mesmo corpus e (ii) da seleção de variáveis que não foram consideradas anteriormente, como classe gramatical, escolaridade e faixa etária.

Deve-se destacar, todavia, que esses quatro trabalhos consideram somente as vogais médias pretônicas internas, como em pr[i]cisa e b[u]né, ou seja, excluem de suas análises as vogais em início de vocábulo. As autoras justificam essa escolha com base no trabalho de Bisol (1981), que, ao tratar das vogais médias pretônicas em diferentes variedades gaúchas, afirma que os princípios que regem o alçamento das pretônicas em início de vocábulo são diferentes daqueles que atuam em prol do alçamento das pretônicas internas. Desse modo, a autora defende que, dada sua complexidade, as vogais iniciais devam ser estudadas à parte. Portanto, para o preenchimento dessa lacuna, o presente trabalho analisa as vogais médias pretônicas em início de vocábulo.

Destaca-se, por fim, o vínculo desta pesquisa ao projeto PROBRAVO - Descrição SócioHistórica das Vogais do Português (do Brasil) -, coordenado pelos professores doutores Seung-Hwa Lee (FALE/UFMG) e Marco Antônio de Oliveira (PUC/MG), que realiza investigações sócio-históricas e linguísticas sobre as realizações fonéticas das vogais em diversas variedades do PB.

O presente artigo está estruturado da seguinte maneira: inicialmente, apresenta-se o arcabouço teórico que embasa esta pesquisa, tanto no que se refere a estudos sobre vogais médias pretônicas, quanto à Teoria da Variação e Mudança Linguística (LABOV, 2008 [1972]). Em seguida, faz-se a descrição do córpus e da metodologia empregados nesta pesquisa. Posteriormente, é realizada a análise dos dados acerca das vogais médias pretônicas iniciais na variedade do noroeste paulista. Por fım, são apresentadas as considerações finais, seguidas pelas referências bibliográfıcas.

\section{Arcabouço teórico}

A complexidade das vogais do Português é destacada por Câmara Jr. (2007 [1970], p. 39), o qual afırma que "a realidade da língua oral é muito mais complexa do que dá a entender o uso aparentemente simples e regular das cinco letras latinas vogais na escrita. O que há são 7 fonemas vocálicos multiplicados em muitos alofones". A partir de suas constatações sobre a variedade do Rio de Janeiro, o autor afirma haver sete vogais orais em posição tônica no PB, sendo elas: /u/, /o/, /o/, /a/, / / /, /e/ e /i/. Em posições átonas, no entanto, ocorre uma redução do número de fonemas, por meio do processo de neutralização. Na posição pretônica, conforme observa o autor, há uma redução de sete para cinco fonemas vocálicos: /u/, /o/, /a/, /e/ e /i/. 
Na variedade do noroeste paulista, as vogais médias pretônicas em início de vocábulo, assim como as médias pretônicas em meio de palavra, estão sujeitas ao alçamento vocálico, por meio do qual as vogais /e/ e /o/ são pronunciadas [i] e [u], respectivamente, como em [i]scola e [u]spital. Dois processos podem acarretar a aplicação do alçamento: (i) harmonização vocálica (CÂMARA JR., 2007 [1970]; BISOL, 1981), em que a presença de uma vogal alta na sílaba seguinte à da pretônica-alvo funciona como gatilho à aplicação do alçamento, como em [i]xiste e [u]rgu/hoso; e/ou (ii) redução vocálica (ABAURREGNERRE, 1981), em que, geralmente, verifica-se a influência do ponto de articulação da(s) consoante(s) adjacente(s) à pretônica-alvo para a realização do fenômeno, como em [ik]onomia e [uk]asião.

Corroborando a afirmação de Bisol (1981), algumas pesquisas sobre vogais pretônicas que consideram o contexto de início de vocábulo têm constatado um comportamento diferenciado por parte dessas vogais, quando comparadas às pretônicas internas. Battisti (1993), por exemplo, retoma o trabalho de Bisol (1981) ao tratar do comportamento das vogais médias pretônicas nos contextos excluídos por esta autora, dentre eles, as vogais médias pretônicas em início de vocábulo. ${ }^{3}$ Battisti (1993, p. 95) observa que "a

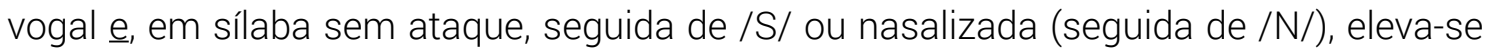
quase que categoricamente". Conforme atesta a autora, na fala gaúcha, o alçamento da vogal pretônica /e/ nesse contexto está em vias de se tornar categórico. Em relação à pretônica /o/ em início de vocábulo, a autora constata uma maior resistência à aplicação do fenômeno, afirmando que "a vogal o em sílaba sem ataque tende a ser preservada" (BATTISTI, 1993, p. 95).

Poucos estudos se dedicam exclusivamente à análise das vogais médias pretônicas em início de vocábulo. Um exemplo desses estudos é o recente trabalho de Brandão, Rocha e Santos (2012) acerca das vogais médias pretônicas iniciais na variedade de Nova Iguaçu (RJ). Para a pretônica /e/, as autoras observam índice de alçamento de 73\% e constatam, a partir da consideração de variáveis extralinguísticas, que o fenômeno se encontra em fase final de mudança. Em relação à vogal pretônica /o/ em início de vocábulo, as autoras encontram taxa de alçamento de apenas 1\%, correspondente a duas ocorrências de alçamento ([u]spitais e [u]bjetivo). Por fim, destacam a "necessidade de focalizar as pretônicas de forma atomística, isto é, em contextos específicos no âmbito do vocábulo" (BRANDÃO; ROCHA; SANTOS, 2012, p. 286).

Como pode ser observado, as investigações acerca de vogais médias pretônicas iniciais em diferentes variedades do PB, de modo geral, parecem compartilhar de dois resultados. $O$ primeiro diz respeito à alta frequência de alçamento em vogais médias

3 Além das vogais médias pretônicas em início de vocábulo, Battisti (1993) investiga essas vogais nos seguintes contextos: (i) hiato (t[e]atro t[i]atro); (ii) prefixo (d[e]sconfiado d[i]sconfiado); e (iii) início de palavra ([e]letricista [i]letricista). 
pretônicas /e/ iniciais seguidas por /S/ ou /N/ em coda silábica, como em [i]special e [i]mprego. Sobre esse contexto, Battisti (1993) destaca uma menor distância da pretônicaalvo em relação à sílaba tônica como possível fator favorecedor do alçamento. Além disso, justifica o resultado com base na qualidade da consoante seguinte à pretônicaalvo, que pode promover o alçamento por redução vocálica. Do mesmo modo, Brandão, Rocha e Santos (2012) justificam resultado semelhante com base nos fatos de: (i) na variedade carioca de Nova Iguaçu, o /S/ em coda silábica ser produzido principalmente como [S], que, segundo as autoras, apresenta traço vocálico; e (ii) a vogal pretônica /e/, quando em sílaba travada por /N/, aproximar-se da área da vogal alta [i], por aumento das frequências dos formantes altos, como atesta Bisol (1981).

O segundo resultado que os estudos sobre vogais médias pretônicas em início de vocábulo em determinadas variedades do PB apontam é a manutenção da vogal média /o/ inicial, como em [o]lhou e [o]portunidade. Brandão, Rocha e Santos (2012) explicam esse resultado com base na estrutura da sílaba, pois, em seus dados, a maioria dessas ocorrências corresponde à estrutura sem elemento em coda, fator que apresenta baixa frequência de alçamento.

Notam-se, portanto, resultados distintos para as pretônicas /e/ e /o/ em início de vocábulo. Esses resultados diferem, também, dos índices percentuais geralmente obtidos quando consideradas as vogais médias pretônicas internas, os quais se encontram aproximadamente entre $10 \%$ e $35 \%$, para ambas as vogais. ${ }^{4}$

Os estudos que consideram as vogais médias pretônicas em início de vocábulo não costumam explorar o contexto precedente a essa vogal. ${ }^{5}$ Uma das hipóteses da presente pesquisa é a de que o alçamento da vogal média pretônica inicial também pode ser influenciado pelo último segmento do vocábulo anterior à pretônica em início de palavra. Na ausência de pausa antes da realização da vogal média pretônica inicial, o vocábulo anterior terminado em consoante pode influenciar o alçamento da pretônica inicial por meio de redução vocálica. No caso de o vocábulo precedente terminar em vogal, podem ocorrer processos de sândi externo, ${ }^{6}$ processo de ressilabificação motivada por choque dos núcleos de sílabas de vocábulos diferentes (BISOL, 2002; TENANI, 2002). Com a variável linguística contexto precedente à pretônica-alvo (cf. seção seguinte deste artigo),

4 Em contexto de vogal em posição interna da palavra, Bisol (1981), por exemplo, obteve índices de alçamento de 22\% para /e/ e 32\% para /o/ na fala popular do Rio Grande do Sul e de $21 \%$ para /e/ e 22\% para /o/ na fala culta gaúcha. Em relação à variedade do noroeste paulista, Carmo (2013, 2014) e Carmo e Tenani (2013) constataram a realização do fenômeno em 16,1\% das ocorrências de pretônica /e/ e em 16,6\% das ocorrências de /o/.

5 Bisol (1981) limita-se a afirmar que o silêncio à esquerda da pretônica /e/ seguida por /N/ ou /S/ é um ambiente favorecedor do alçamento dessa vogal.

6 A saber: degeminação, elisão e ditongação (TENANI, 2002). 
testa-se a hipótese de que essas informações são relevantes no que diz respeito ao alçamento vocálico.

A análise do alçamento vocálico das vogais médias pretônicas em início de vocábulo na variedade do noroeste paulista fundamenta-se na Teoria da Variação e Mudança Linguística (LABOV, 2008 [1972]), também denominada Sociolinguística Quantitativa. Labov (2008 [1972]) propõe uma teoria linguística que abarque a língua em uso dentro da comunidade de fala, com a variação linguística regular e inerente ao sistema, condicionada por fatores linguísticos e sociais. Nesse sentido, esse modelo teórico distancia-se da tradição estruturalista proposta por Saussure no início do século XX, apontando o paradoxo saussuriano de o aspecto social da língua ser estudado ao se analisar qualquer indivíduo, enquanto o aspecto individual, apenas pela observação da língua em contexto social.

De forma geral, Labov (2008 [1972]) critica a tradição linguística estruturalista e gerativista de analisar uma suposta homogeneidade linguística, desconsiderando o estudo do comportamento social da língua em uso. Nesse âmbito, propõe, como objeto de estudos, a heterogeneidade da língua, concebida como instrumento de comunicação utilizado pela comunidade de fala.

A mudança linguística, segundo essa teoria, relaciona-se diretamente ao processo de variação linguística, pois a pressupõe. Na variação, tem-se que o repertório linguístico do(a) falante engloba determinadas variantes de uma mesma variável. No entanto, pode haver um desfavorecimento gradual de determinada variante em prol de outra, de modo que a primeira se torna obsoleta, deixando de ser usada, implementando-se, dessa forma, a mudança linguística (COELHO et al., 2015).

Para Labov (2008 [1972]), a mudança tende a se implementar, com as regras variáveis tornando-se invariantes. Porém, nem todos os processos variáveis sofrem mudança. Coelho et al. (2015) exemplificam o rotacismo, como em p[R]anta p[I]anta, como um fenômeno variável sem indicativo de mudança em progresso no PB.

A mudança linguística pode ser explicada segundo dois modelos divergentes: o modelo da difusão lexical e o neogramático. De acordo com o modelo difusionista, cada vocábulo apresenta sua história e as mudanças, implementadas a partir do léxico, são foneticamente abruptas e lexicalmente graduais. O modelo neogramático, por sua vez, propõe que todas as palavras sejam atingidas indistintamente pela mudança linguística (mudanças lexicalmente abruptas e foneticamente graduais) e que as eventuais exceções à regra possam ser explicadas por analogia. Por apresentarem condicionadores fonéticos, Bisol (2009) classifica como neogramáticos o alçamento da pretônica /e/ inicial seguida por /N/ ou /S/ e a harmonização vocálica da vogal média pretônica. Já a redução vocálica, segundo a autora, consiste em um processo difusionista, "cuja expansão deve ser o produto da ação analógica do falante" (BISOL, 2009, p. 76). 
Com base no arcabouço teórico brevemente descrito, é realizada a presente investigação, que emprega a metodologia explicitada na próxima seção.

\section{Material e métodos}

O córpus utilizado nesta pesquisa é formado por 38 entrevistas ${ }^{7}$ do banco de dados IBORUNA, resultado do projeto ALIP - Amostra Linguística do Interior Paulista ${ }^{8}$ FAPESP 03/08058-6, IBILCE/UNESP (GONÇALVES, 2013). O banco de dados IBORUNA é constituído por amostras de fala espontânea de informantes oriundos do noroeste paulista, mais precisamente do município de São José do Rio Preto e de seis cidades circunvizinhas: Bady Bassit, Cedral, Guapiaçu, Ipiguá, Mirassol e Onda Verde.

O banco de dados é composto de dois tipos de amostras: amostra censo linguístico e amostra de interação dialógica. Nesta pesquisa, é considerada apenas a primeira, por ser aquela que controla os perfis sociais dos informantes. A amostra censo linguístico é constituída por gravações de 152 informantes, cujos perfis sociais resultaram das diferentes combinações entre as variáveis sociais sexo/gênero (masculino e feminino), escolaridade ( $1^{\circ}$ ciclo do Ensino Fundamental, $2^{\circ}$ ciclo do Ensino Fundamental, Ensino Médio e Ensino Superior), faixa etária (de 7 a 15 anos, de 16 a 25 anos, de 26 a 35 anos, de 36 a 55 anos e acima de 55 anos) e renda familiar (até 5 salários-mínimos, de 6 a 10 salários-mínimos, de 11 a 24 salários-mínimos e superior a 24 salários-mínimos).

O presente estudo considera, como variável dependente, a ocorrência e a não-ocorrência do alçamento das vogais médias pretônicas iniciais na variedade do noroeste paulista. No que diz respeito às variáveis independentes, analisam-se dez, a saber:

(i) Sexo/gênero - Em geral, as pesquisas sociolinguísticas têm constatado que as mulheres usam variantes estigmatizadas e não-padrão com menos frequência do que os homens do mesmo grupo social a que pertencem (LABOV, 2008 [1972]; CHAMBERS, 2009 [1995]). A variável sexo/gênero é considerada na presente pesquisa, portanto, a fim de se verificar se há diferentes manifestações de vogais médias pretônicas iniciais na fala de homens e de mulheres e eventual indício de estigma a itens lexicais que apresentam o alçamento;

7 No banco de dados IBORUNA, cada perfil é representado por um informante apenas. Logo, dos 40 inquéritos possíveis inicialmente (2 gêneros $\times 4$ graus de escolaridade $\times 5$ faixas etárias), não é possível ter informantes - tanto do sexo/gênero masculino quanto do feminino - de faixa etária de 7 a 15 anos que apresentem Ensino Superior.

8 A autora participou desse projeto como integrante da equipe técnica responsável pela gravação dos inquéritos e pela transcrição ortográfica dos dados, possuindo bolsa de Capacitação Técnica da FAPESP (Proc. 04/02962-5), no período de julho/2004 a fevereiro/2006. 
(ii) Escolaridade - Busca-se averiguar se, na fala de informantes com menos anos de escolaridade, pode haver um conjunto de dados diferente daquele de informantes com maior escolaridade: por exemplo, algum dado em variação que não é encontrado na fala de informantes que apresentam Ensino Superior;

(iii) Faixa etária - A consideração de diferentes faixas etárias permite a realização de um estudo em tempo aparente, averiguando o status do fenômeno variável como variação estável ou como mudança em progresso. Se, quanto mais jovem a faixa etária, maior a aplicação do fenômeno, tem-se um indício de que o fenômeno esteja em vias de mudança. Por outro lado, se houver diferentes faixas etárias com usos relativamente similares de determinada variante, há um indício de variação estável;

(iv) Altura da vogal presente na sílaba subsequente à da pretônica-alvo - Com essa variável, pode-se verificar uma possível influência da presença de uma vogal alta na sílaba seguinte, a qual funciona como gatilho à harmonização vocálica, como em [i]xiste, [i]scuro, [u]spital e [u]rgulhoso;

(v) Distância entre a sílaba inicial e a sílaba tônica - Por meio dessa variável, testa-se a hipótese de que a adjacência da sílaba inicial em relação à tônica, como em [i]scola e [u]rário, favorece a aplicação do alçamento (BATTISTI, 1993);

(vi) Contexto precedente à pretônica-alvo - Para ser testada a hipótese de que o alçamento sofre influência do contexto precedente à pretônica inicial, investiga-se a atuação de elementos como a pausa e o último segmento do vocábulo precedente;

(vii) Contexto subsequente à pretônica-alvo - Objetiva-se verificar uma possível influência do ponto de articulação da consoante seguinte em prol do alçamento vocálico, por meio de redução vocálica. Na literatura sobre o tema, é consenso que, em posição adjacente à pretônica-alvo, consoantes com ponto de articulação alto - como as velares, como em [ik]onomia -, tendem a favorecer o alçamento dessa vogal, ao passo que consoantes com ponto de articulação baixo - como as alveolares, como em o[re]lhão -, tendem a inibi-lo;

(viii) Estrutura da sílaba - Com a consideração dessa variável, em que se utiliza a noção de sílaba proposta por Collischonn (1999), com base em Selkirk (1982), para o Português, busca-se analisar a estrutura da sílaba em que a pretônica-alvo está inserida, com o intuito de verificar se a vogal anterior inicial com elemento /S/ ou /N/ em coda, como em [i]stagiários e [i]mprego, é a que apresenta o alçamento com maior frequência, como constatado para outras variedades do PB (BISOL, 1981; BATTISTI, 1993; BRANDÃO; ROCHA; SANTOS, 2012); 
(ix) Localização da vogal pretônica-alvo - Bisol (1981) e Collischonn (2006) afirmam que, entre o prefixo que mantém as características semânticas do vocábulo original e o restante do vocábulo, há uma fronteira de palavras a qual a harmonização vocálica não atravessa. Seria de se esperar, então, que pretônicas em prefixos tivessem baixas porcentagens de alçamento. No entanto, Battisti (1993) observa que pretônicas em prefixo em-/en-, como em [i]nfaixou, ou ex-/es-, como em [i]s clareci, têm altas porcentagens de alçamento na fala gaúcha. Para uma investigação mais detalhada desse contexto, considera-se a localização da vogal pretônica-alvo; e

(x) Grau de atonicidade da pretônica-alvo - Variável considerada com base na afırmação de Bisol (1981) de que a atonicidade permanente da vogal, como, por exemplo, em [i]xpliquei - [i]xplico e [u]rganizada - [u]rganização, tende a ser favorecedora do alçamento. Já o fato de as vogais se apresentarem como tônicas em outras formas do mesmo paradigma, como em [e]ntrei - [e]ntro e [o] Ihada - [o]lho, desfavorece a realização do fenômeno.

Após a seleção do corpus e extração de cada ocorrência de vogal média pretônica inicial juntamente com o contexto em que estava inserida, identificou-se o comportamento dessas vogais. Procedeu-se à análise de oitiva ${ }^{9}$ desses dados e, posteriormente, à análise quantitativa, com o auxílio do pacote estatístico Goldvarb X.

\title{
Análise dos dados
}

Os resultados gerais do alçamento das vogais médias pretônicas em início de vocábulo no noroeste paulista são apresentados na tabela 1.

Tabela 1. Aplicação geral do alçamento ${ }^{10}$

\begin{tabular}{c|c|c|c}
\hline \multicolumn{2}{c|}{ Pretônica /e/ } & \multicolumn{2}{c}{ Pretônica /o/ } \\
\hline Frequência & Peso relativo & Frequência & Peso relativo \\
\hline $76,8 \%(2329 / 3033)$ & 0.715 & $1,7 \%(9 / 518)$ & 0.005 \\
\hline
\end{tabular}

Fonte: Elaboração própria.

\begin{abstract}
9 Cabe destacar que a utilização do banco de dados IBORUNA possibilita a condução de análise de oitiva, somente. Isso se deve à pouca qualidade acústica das gravações provenientes desse banco de dados por, nelas, serem encontrados muitos ruídos, decorrentes do fato de as entrevistas não terem sido realizadas em cabines com isolamento acústico. Desse modo, torna-se inexequível a realização de análise acústica das ocorrências provenientes desse banco de dados.

10 Os valores de input e significância, para a tabela 1, são 0.726 e 0.011 , respectivamente. Para as demais tabelas, são 0.950 e 0.012, respectivamente, para /e/, e 0.000 e 0.039 , respectivamente, para $/ 0 /$.
\end{abstract}


Em uma primeira rodada, foram analisadas, concomitantemente, todas as ocorrências de vogais médias pretônicas, a fim de se observar o comportamento da variável vogal pretônica-alvo. Como esperado, essa variável foi selecionada relevante para a aplicação do alçamento das vogais médias pretônicas iniciais na variedade estudada, com frequência e peso relativo (doravante, PR) altos (76,8\% e 0.715 , respectivamente) para a pretônica anterior, como em [i]stágio e [i]xemplo, e baixos (1,7\% e 0.005, respectivamente) para a posterior, como em [o]bjetivo e [o]pinião.

Esses resultados gerais sobre o alçamento das vogais médias pretônicas em início de vocábulo no noroeste paulista vão ao encontro dos resultados verificados por estudos sobre pretônicas iniciais em outras variedades do PB já citados neste trabalho: alta frequência de alçamento da vogal pretônica anterior e manutenção da posterior (BISOL, 1981; BATTISTI, 1993; BRANDÃO; ROCHA; SANTOS, 2012). No que tange à variedade de Nova Iguaçu (RJ), por exemplo, Brandão, Rocha e Santos (2012) constataram índices de alçamento bastante próximos aos encontrados na presente pesquisa: $73 \%$ para /e/ e 1\% para /o/.

Evidenciam-se, portanto, comportamentos divergentes em relação ao alçamento quando comparados os sistemas linguísticos de /e/ e /o/ iniciais, o que justifica as rodadas posteriores efetuadas na pesquisa, com análises independentes para cada vogal média pretônica em início de vocábulo.

Antes da apresentação dos resultados dessas rodadas, cabe a comparação do alçamento das vogais médias pretônicas iniciais e mediais (CARMO, 2013, 2014; CARMO; TENANI, 2013) na variedade do noroeste paulista. Nas vogais médias pretônicas internas, como em pr[i]cisa e imp[u]ssível, as autoras apontam taxas de alçamento bastante próximas entre si, mas divergentes das apresentadas nesta investigação: 16,1\% para /e/ e 16,6\% para /o/. Esses resultados iniciais já demonstram os comportamentos diferenciados de vogais médias pretônicas em contextos inicial e medial de vocábulo, corroborando a afirmação de Bisol (1981) de que essas vogais devam ser investigadas separadamente.

No que concerne à seleção de variáveis pelo programa estatístico, tem-se o quadro 1, apresentado a seguir. 
Quadro 1. Seleção de variáveis pelo programa estatístico ${ }^{11}$

\begin{tabular}{|l|c|c|}
\hline \multicolumn{1}{|c|}{ Variável } & /e/ & /o/ \\
\hline Sexo/gênero & $\varnothing\left(7^{\mathrm{a}}\right)$ & $\varnothing\left(3^{\mathrm{a}}\right)$ \\
\hline Escolaridade & $5^{\mathrm{a}}$ & $1^{\mathrm{a}}$ \\
\hline Faixa etária & $\varnothing\left(3^{\mathrm{a}}\right)$ & $\varnothing\left(1^{\mathrm{a}}\right)$ \\
\hline $\begin{array}{l}\text { Altura da vogal presente na sílaba subsequente à da } \\
\text { pretônica-alvo }\end{array}$ & $4^{\mathrm{a}}$ & $2^{\mathrm{a}}$ \\
\hline Distância entre a sílaba inicial e a sílaba tônica & $\varnothing\left(2^{\mathrm{a}}\right)$ & $3^{\mathrm{a}}$ \\
\hline Contexto precedente à pretônica-alvo & $3^{\mathrm{a}}$ & $4^{\mathrm{a}}$ \\
\hline Contexto subsequente à pretônica-alvo & $7^{\mathrm{a}}$ & $\varnothing\left(2^{\mathrm{a}}\right)$ \\
\hline Estrutura da sílaba & $1^{\mathrm{a}}$ & $5^{\mathrm{a}}$ \\
\hline Localização da vogal pretônica-alvo & $6^{\mathrm{a}}$ & Eliminada $^{12}$ \\
\hline Grau de atonicidade da pretônica-alvo & $2^{\mathrm{a}}$ & Eliminada $^{13}$ \\
\hline
\end{tabular}

Fonte: Elaboração própria.

Para /e/, as variáveis selecionadas como mais relevantes foram, em ordem decrescente: (i) estrutura da sílaba; (ii) grau de atonicidade da pretônica-alvo; (iii) contexto precedente à pretônica-alvo; (iv) altura da vogal presente na sílaba subsequente à da pretônica-alvo; (v) escolaridade; (vi) localização da vogal pretônica-alvo; e (vii) contexto subsequente à pretônica-alvo. Por sua vez, para /o/, foram selecionadas, também em ordem decrescente: (i) escolaridade; (ii) altura da vogal presente na sílaba subsequente à da pretônica-alvo; (iii) distância entre a sílaba inicial e a sílaba tônica; (iv) contexto precedente à pretônica-alvo; e (v) estrutura da sílaba.

De modo geral, destaca-se a não-seleção das variáveis extralinguísticas sexo/gênero e faixa etária, tanto para /e/ quanto para /o/. A exclusão do sexo/gênero poderia indicar, a princípio, que o fenômeno variável não é estigmatizado socialmente, tendo em vista (i) o

11 No quadro 1, o símbolo " Ø" indica que a variável não foi selecionada pelo programa estatístico. Entre parênteses, tem-se a ordem de descarte da variável pelo programa.

12 Devido à existência de ocorrências em apenas um fator.

13 Devido a nocaute (0, de 123 ocorrências) em um fator (de um total de dois fatores). 
fato de não haver diferença significativa em relação à aplicação do fenômeno na fala de homens e de mulheres na variedade do noroeste paulista; e (ii) como apresentado neste trabalho, estudos sociolinguísticos apontam que as mulheres costumam utilizar variantes estigmatizadas com menor frequência do que os homens de seu grupo social (LABOV, 2008 [1972]; CHAMBERS, 2009 [1995]). Entretanto, para se confırmar tal afırmação, seria necessária a realização de teste de avaliação das formas variantes, o que é deixado para futuras pesquisas. Por sua vez, a não-seleção da faixa etária indica que o fenômeno variável se encontra em variação estável, o que pode ser afırmado especificamente para /e/, dada a taxa de aplicação não-categórica de 76,8\%.

Passa-se, agora, à análise de cada uma das variáveis selecionadas como relevantes ao alçamento de /e/ e /o/ pretônicas em início de vocábulo no noroeste paulista.

Tabela 2. Aplicação do alçamento em relação à estrutura da sílaba

\begin{tabular}{c|c|c|c|c}
\cline { 2 - 5 } \multicolumn{2}{c}{} & \multicolumn{2}{c|}{ Pretônica /e/ } & \multicolumn{2}{c}{ Pretônica /o/ } \\
\cline { 2 - 5 } & Frequência & Peso relativo & Frequência & Peso relativo \\
\hline $\mathrm{V}+\mathrm{V} / \mathrm{R} /{ }^{14}$ & $17,8 \%(107 / 600)$ & 0.007 & $1,8 \%(8 / 449)$ & 0.306 \\
\hline $\mathrm{V} / \mathrm{N} /$ & $79,2 \%(773 / 976)$ & 0.518 & --- & - --.-15 $^{15}$ \\
\hline $\mathrm{V} / \mathrm{S} /$ & $99,5 \%(1449 / 1457)$ & 0.881 & $1,4 \%(1 / 69)$ & 0.995 \\
\hline
\end{tabular}

Fonte: Elaboração própria.

Em relação à estrutura da sílaba, o quadro 1 assinala que essa variável foi selecionada como a mais relevante para o alçamento de /e/ e a quinta para a aplicação do fenômeno em /o/. Para /e/, verifica-se que o contexto de pretônica seguida por consoante sibilante em coda, como em [i]s. co.la e [i]s. fa.re.la, favorece a aplicação do processo, com PR 0.881. Já o contexto silábico de pretônica /e/ seguida por consoante nasal, como em [e]n.trar e [i]n.tu.piu, mostra-se relativamente neutro em relação à aplicação do alçamento, com PR 0.518. Cabe destacar, contudo, a frequência relativamente alta de aplicação do fenômeno nesse contexto: $79,2 \%$. Esse resultado pode ser explicado pelo aumento das frequências dos formantes 2 e 3 quando a vogal pretônica /e/ apresenta-se em sílaba travada por /N/, aproximando-se, portanto, da área da vogal alta [i] (BISOL, 1981). Por fim, verifica-se

14Ressalta-se que,especificamentepara/e/,ocorreu o amálgama também do fator correspondente à vogal pretônica seguida por /// (com vocalização em sua realização fonética), devido a uma ocorrência do vocábulo [e]lmaz, nome próprio de um bairro do município de São José do Rio Preto (SP).

15 Não houve ocorrências de vogal pretônica /o/ inicial seguida por consoante nasal em coda silábica. 
o bloqueio da aplicação da regra nos demais contextos silábicos, como em [e].le.trô.ni.co e [e]r.guer, com PR 0.007.

Esses resultados referentes à variedade do noroeste paulista se aproximam daqueles obtidos para o falar gaúcho (BATTISTI, 1993) e de Nova Iguaçu (BRANDÃO; ROCHA; SANTOS, 2012). Todavia, para a variedade carioca, como anteriormente apresentado neste artigo, as autoras associam a alta frequência de alçamento da pretônica /e/ inicial seguida por /S/ ao traço vocálico da realização fonética [S]. Vale destacar que, nesse contexto, essa pronúncia não é frequente na variedade do noroeste paulista, estando limitada ao contexto em que precede uma consoante oclusiva alveolar palatalizada, como em [iS].ti.lo e [iS].ti.ma.ção.

Para /o/, atesta-se o favorecimento da aplicação do fenômeno (PR 0.995) para a estrutura silábica com /S/ em coda, como em [u]s.pi.tal, e o desfavorecimento (PR 0.306) para o contexto de vogal /o/ em sílaba aberta ou seguida por /R/ em coda, como em [o].fen.sas e [o]r.ga.nis.mo, respectivamente. No entanto, esse resultado deve ser relativizado pela escassez de dados referentes à vogal média pretônica posterior em início de vocábulo (518 ocorrências, com apenas nove casos de alçamento), o que pode enviesar os resultados estatísticos concernentes a essa vogal.

A variável grau de atonicidade da pretônica-alvo não foi selecionada para o alçamento da pretônica /o/ inicial na variedade do noroeste paulista. Já para /e/, foi apontada como a segunda mais relevante, e os resultados de seus fatores são apresentados na tabela 3.

Tabela 3. Aplicação do alçamento em relação ao grau de atonicidade da pretônica-alvo

\begin{tabular}{c|c|c}
\hline \multicolumn{3}{c}{ Pretônica /e/ } \\
\hline & Frequência & Peso relativo \\
\hline Atonicidade permanente & $82,7 \%(2324 / 2810)$ & 0.636 \\
\hline Atonicidade variável & $2,2 \%(5 / 223)$ & 0.001 \\
\hline
\end{tabular}

Fonte: Elaboração própria.

A atonicidade permanente da vogal, como em [i]mpresa e [i]xame, favorece o alçamento da pretônica inicial (PR 0.636). Por outro lado, a natureza variável da atonicidade da vogal, como em [e]rguer e [e]ntrava, bloqueia a aplicação do fenômeno (PR 0.001). Esse resultado corrobora, para a pretônica /e/ na variedade do noroeste paulista, a afirmação de Bisol (1981) de que o caráter permanentemente átono da vogal é um fator favorecedor do alçamento. 
Em relação ao contexto precedente à pretônica-alvo, selecionado como terceira e quarta variável mais relevante para o alçamento de /e/ e /o/, respectivamente, deve-se salientar que os fatores expostos na tabela 4 apresentam as formas de superfície efetivamente obtidas a partir do levantamento dos dados.

Tabela 4. Aplicação do alçamento em relação ao contexto precedente à pretônica-alvo

\begin{tabular}{|c|c|c|c|c|}
\hline & \multicolumn{2}{|c|}{ Pretônica /e/ } & \multicolumn{2}{|c|}{ Pretônica /o/ } \\
\hline & Frequência & Peso relativo & Frequência & Peso relativo \\
\hline Tônica [i] & $86,5 \%(32 / 37)$ & 0.834 & \multirow[t]{3}{*}{$4,5 \%(5 / 110)$} & \multirow[t]{3}{*}{0.813} \\
\hline Átona [i] & $77,6 \%(389 / 501)$ & 0.628 & & \\
\hline Glide [I] & $74,1 \%(100 / 135)$ & 0.469 & & \\
\hline Tônica [u] & $81,9 \%(95 / 116)$ & 0.861 & \multirow[t]{3}{*}{$1,1 \%(2 / 179)$} & \multirow[t]{3}{*}{0.703} \\
\hline Átona [u] & $79,5 \%(310 / 390)$ & 0.459 & & \\
\hline Glide [U] & $81,5 \%(172 / 211)$ & 0.434 & & \\
\hline Tônica [e] & $87,6 \%(85 / 97)$ & 0.687 & \multirow[t]{7}{*}{$0,9 \%(2 / 229)$} & \multirow[t]{7}{*}{0.201} \\
\hline Tônica [o] & $83,3 \%(40 / 48)$ & 0.825 & & \\
\hline Tônica [E] & $75 \%(51 / 68)$ & 0.594 & & \\
\hline Tônica [a] & $79,6 \%(320 / 402)$ & 0.263 & & \\
\hline Átona [a] & $76,3 \%(357 / 468)$ & 0.410 & & \\
\hline Consoante coronal & $57,6 \%(179 / 311)$ & 0.509 & & \\
\hline Pausa & 79,9\% (199/249) & 0.500 & & \\
\hline
\end{tabular}

Fonte: Elaboração própria.

Para /e/, a presença de uma vogal tônica, como em aí [i]ncaminhava, favorece o alçamento (especialmente a presença de vogais altas [i] e [u] - PRs 0.834 e 0.861, respectivamente). Uma exceção é a vogal tônica [a], que desfavorece a aplicação do fenômeno (PR 0.263), como em tá [e]sperando. Em relação às vogais átonas, [i], como em me [i]nsinou, favorece (PR 0.628), [u], como em filho escolheu, é neutra (PR 0.459) e [a], como em bicicleta [e]rgométrica, desfavorece a aplicação do fenômeno (PR 0.410). Pausa, como em ... [i]ntregar, e consoante coronal, como em mais [e]conômica, são neutras em relação ao alçamento da vogal média pretônica [e] (PRs 0.500 e 0.509, respectivamente). 
Por sua vez, para /o/, o amálgama de fatores foi necessário devido ao número significativo de nocautes. Os resultados demonstram que as realizações de vogais altas anteriores, como em gente [u]bedecia, e posteriores, como em no [u]spital, em contexto precedente favorecem o alçamento de /o/ (PRs 0.813 e 0.703, respectivamente), enquanto os outros contextos, como a pausa, como em ... [o]bcecada, desfavorecem a aplicação do fenômeno (PR 0.201).

No que tange aos processos de sândi externo (BISOL, 2002; TENANI, 2002), podese destacar a degeminação, como em pod[i]ntregar e amig[u]fereceu, cujos contextos favorecem o alçamento tanto de /e/ quanto de /o/.

Na tabela 5, são apresentados os resultados relativos à altura da vogal presente na sílaba subsequente à da pretônica-alvo, selecionada como quarta e segunda variável mais relevante para o alçamento, respectivamente, de /e/ e /o/.

Tabela 5. Aplicação do alçamento em relação à altura da vogal presente na sílaba subsequente à da pretônica-alvo

\begin{tabular}{|c|c|c|c|c|}
\hline & \multicolumn{2}{|c|}{ Pretônica /e/ } & \multicolumn{2}{|c|}{ Pretônica /o/ } \\
\hline & Frequência & Peso relativo & Frequência & Peso relativo \\
\hline Altas & $78,4 \%(554 / 707)$ & 0.473 & $0,4 \%(1 / 226)$ & 0.112 \\
\hline Médias-altas & $75,7 \%$ (930/1228) & 0.428 & $5,6 \%(7 / 126)$ & 0.983 \\
\hline Médias-baixas & \multirow{2}{*}{$77 \%(845 / 1098)$} & \multirow{2}{*}{0.597} & \multirow{2}{*}{$0,6 \%(1 / 166)$} & \multirow{2}{*}{0.436} \\
\hline Baixas & & & & \\
\hline
\end{tabular}

Fonte: Elaboração própria.

Tanto para a vogal pretônica /e/, quanto para /o/, devido a nocautes, foram necessários os amálgamas entre (i) vogais altas anterior e posterior; e (ii) vogais médias-baixas e baixa. Para a vogal pretônica /e/, a princípio, a vogal baixa na sílaba seguinte à da pretônicaalvo, como em [i]ngraçado, apresenta-se como favorecedora da aplicação do alçamento (PR 0.597). Todavia, apesar de a variável ter sido selecionada pelo programa estatístico, atestam-se PRs relativamente próximos ao ponto neutro (0.428 e 0.473 , para vogais médias-altas e altas, respectivamente). Esses resultados indiciam que o alçamento das vogais médias pretônicas em início de vocábulo na variedade do noroeste paulista é resultado, sobretudo, do processo de redução vocálica (ABAURRE-GNERRE, 1981), sendo a harmonização vocálica (CÂMARA JR., 2007 [1970]; BISOL, 1981) um processo secundário na aplicação do fenômeno. 
No que se refere à pretônica /o/, vogais altas na sílaba seguinte, como em [o]rrível, desfavorecem o alçamento (PR 0.112) e vogais médias-altas, como em [o]perar, apesar do PR alto (0.983), não engatilham o alçamento via harmonização vocálica. Consequentemente, verifica-se, também para a pretônica posterior, a influência do processo de redução vocálica. Tendo em vista a possibilidade de os resultados estatísticos estarem enviesados pelo baixo número de dados, analisam-se as nove ocorrências de alçamento da vogal pretônica /o/ inicial. Como será mostrado mais adiante, apenas uma ([u]spital) pode ser explicada pela influência de uma vogal alta na sílaba subsequente, que engatilha o processo de harmonização vocálica.

Essa atuação da redução vocálica em prol do alçamento das vogais médias pretônicas iniciais no noroeste paulista contrasta com os resultados obtidos por Carmo $(2013,2014)$ e Carmo e Tenani (2013) acerca das pretônicas internas na mesma variedade. As autoras destacam a relevância da harmonização para o alçamento das pretônicas mediais, como em d[i]stino e g[u]rdura. Novamente, atestam-se comportamentos divergentes do alçamento em vogais médias pretônicas em início e em meio de vocábulo.

Na presente investigação, quanto às variáveis extralinguísticas, a escolaridade foi a única variável selecionada para o alçamento de /e/ (quinta posição) e de /o/ (primeira posição) (cf. quadro 1). Os resultados para cada nível de escolaridade são identificados na tabela que segue.

Tabela 6. Aplicação do alçamento em relação à escolaridade

\begin{tabular}{c|c|c|c|c}
\cline { 2 - 5 } & \multicolumn{2}{c|}{ Pretônica /e/ } & \multicolumn{2}{c}{ Pretônica /o/ } \\
\cline { 2 - 5 } & Frequência & Peso relativo & Frequência & Peso relativo \\
\hline $\begin{array}{c}1^{\circ} \text { ciclo do Ensino } \\
\text { Fundamental }\end{array}$ & $78 \%(294 / 377)$ & 0.518 & $10 \%(5 / 50)$ & 0.996 \\
\hline $\begin{array}{c}2^{\circ} \text { ciclo do Ensino } \\
\text { Fundamental }\end{array}$ & $\begin{array}{c}80,5 \% \\
(839 / 1042)\end{array}$ & 0.568 & $0,4 \%(1 / 270)$ & 0.249 \\
\hline Ensino Médio & $73,9 \%(515 / 697)$ & 0.526 & & 0.536 \\
\hline Ensino Superior & $74,3 \%(681 / 917)$ & 0.396 & $1,5 \%(3 / 198)$ & \\
\hline
\end{tabular}

Fonte: Elaboração própria.

Para a pretônica /e/, constatam-se PRs próximos ao ponto neutro para o $1^{\circ}$ e $2^{\circ}$ ciclos do Ensino Fundamental e Ensino Médio (0.518, 0,568 e 0.526, respectivamente). Não obstante, a maior escolaridade do falante (Ensino Superior) desfavorece a aplicação do alçamento da vogal pretônica inicial (PR 0.396). 
Para /o/, foi necessário o amálgama das escolaridades intermediárias ( $2^{\circ}$ ciclo do Ensino Fundamental e Ensino Médio), devido a nocaute ( $0 \%$ de alçamento) no fator correspondente ao Ensino Médio. As escolaridades intermediárias desfavorecem o alçamento (PR 0.249), enquanto o $1^{\circ}$ ciclo do Ensino Fundamental o favorece altamente (PR 0.996). Finalmente, o Ensino Superior mostra comportamento relativamente neutro (PR 0.536).

Os resultados apresentados, especialmente o desfavorecimento do alçamento de /e/ pelo Ensino Superior e o favorecimento do alçamento de /o/ pelo $1^{\circ}$ ciclo do Ensino Fundamental, parecem indicar que esses fenômenos são estigmatizados socialmente. Para uma análise mais sistemática, que confirme ou refute esse resultado preliminar, fazse necessária a aplicação de testes de avaliação social das variantes, o que, por fugir ao escopo do presente trabalho, é deixado para futuras pesquisas.

A tabela 7 expõe os resultados quantitativos relativos à variável localização da vogal pretônica-alvo, selecionada como a sexta mais relevante para o alçamento da vogal pretônica /e/ inicial na variedade do noroeste paulista.

Tabela 7. Aplicação do alçamento em relação à localização da vogal pretônica-alvo

\begin{tabular}{c|c|c}
\hline \multicolumn{3}{c}{ Pretônica /e/ } \\
\hline & Frequência & Peso relativo \\
\hline Raiz & $74,7 \%(2074 / 2776)$ & 0.462 \\
\hline Prefixo & $99,2 \%(255 / 257)$ & 0.839 \\
\hline
\end{tabular}

Fonte: Elaboração própria.

Como descrito na seção anterior, apesar da afırmação de Bisol (1981) e Collischonn (2006) de que a harmonização vocálica não atravessa a fronteira entre determinados prefixos e o restante do vocábulo, eram esperadas taxas altas de alçamento devido à presença dos prefixos em-/en- e ex-/es-, como apontado por Battisti (1993) para a variedade gaúcha. No que concerne à variedade do noroeste paulista, essa hipótese foi confirmada, dada a alta probabilidade (PR 0.839) de alçamento da vogal pretônica /e/ inicial em prefixo, como em [i]ntortou e [i]spalma. Por outro lado, o fato de a vogal pretônica /e/ inicial pertencer à raiz do vocábulo, como em [e]ntrar e [e]stadual, desfavorece levemente a aplicação do fenômeno (PR 0.462). 
Tabela 8. Aplicação do alçamento em relação ao contexto subsequente à pretônica-alvo

\begin{tabular}{c|c|c}
\hline \multicolumn{3}{c}{ Pretônica /e/ } \\
\hline & Frequência & Peso relativo \\
\hline Coronal & $77,4 \%(1882 / 2432)$ & 0.518 \\
\hline Dorsal & $70,1 \%(183 / 261)$ & 0.262 \\
\hline Labial & $77,6 \%(264 / 340)$ & 0.572 \\
\hline
\end{tabular}

Fonte: Elaboração própria.

A variável contexto subsequente à pretônica-alvo foi selecionada apenas para a pretônica inicial /e/, ocupando a sétima - e última - posição. Como ilustra a tabela 8, a consoante labial em posição subsequente à pretônica-alvo, como em [i]mergência, e a consoante coronal, como em [e]xame, mostram-se relativamente neutras em relação ao alçamento (PRs 0.572 e 0.518, respectivamente). Por outro lado, ao contrário do esperado, a consoante dorsal, com em [e]rrou - em que estão englobadas as consoantes velares, que apresentam um ponto de articulação alto -, desfavorece a aplicação do processo (PR 0.262). Apesar disso, deve ser destacada a frequência alta de alçamento de vogal /e/ inicial seguida por consoante dorsal: 70,1\%, o que parece relativizar o resultado referente ao PR.

Por fim, apresentam-se os resultados da distância entre a sílaba inicial e a sílaba tônica, selecionada como a terceira variável mais relevante para o alçamento de /o/.

Tabela 9. Aplicação do alçamento em relação à distância entre a sílaba inicial e a sílaba tônica

\begin{tabular}{c|c|c}
\cline { 2 - 3 } & Prequência & Peso relativo \\
\hline Sílaba adjacente & $1,4 \%(3 / 215)$ & 0.766 \\
\hline Uma sílaba & $0,6 \%(1 / 156)$ & 0.024 \\
\hline Duas sílabas & $2,6 \%(3 / 114)$ & 0.853 \\
\hline Três sílabas & $6,1 \%(2 / 33)$ & 0.976 \\
\hline
\end{tabular}

Fonte: Elaboração própria.

A princípio, esperava-se que a menor distância da pretônica-alvo em relação à sílaba tônica favorecesse o alçamento. No entanto, os resultados quantitativos não corroboram 
essa hipótese. A presença de três sílabas entre a pretônica-alvo e a sílaba tônica, como em [u].por.tu.ni.da.de, mostra-se altamente favorecedora do alçamento (PR 0.976). Em seguida, tem-se a presença de duas sílabas entre as sílabas da pretônica-alvo e a tônica, como em [u].be.de.ci.a, como favorecedora do alçamento (PR 0.853). Enquanto a adjacência da sílaba tônica em relação à pretônica-alvo, como em [u].tel, também favorece o alçamento (PR 0.766), a presença de uma sílaba, como em [o].pe.ra.do, desfavorece fortemente a aplicação da regra (PR 0.024).

Novamente, deve-se ressaltar que os resultados quantitativos relativos à pretônica /o/ inicial parecem estar enviesados pela escassez de dados referentes a esse contexto. Enquanto, em um mesmo córpus, foram identificadas 3033 vogais médias pretônicas /e/ em início de vocábulo, levantaram-se 518 ocorrências de vogal média pretônica /o/ inicial. Além da baixa produtividade, houve apenas nove ocorrências de alçamento, correspondentes a 1,7\% do total. Para uma análise mais apurada do alçamento da vogal média pretônica /o/ em início de vocábulo na variedade do noroeste paulista, listamse as nove ocorrências de aplicação do fenômeno, distribuídas em seis itens lexicais: [u]bedecia (2 ocorrências), [u]fereceu (1 ocorrência), [u]portunidade (2 ocorrências), [u]relha (2 ocorrências), [u]spital (1 ocorrência) e [u]tel (1 ocorrência).

Como já exposto, apesar de a altura da vogal presente na sílaba subsequente à da pretônicaalvo ter sido selecionada como a segunda variável mais relevante para o alçamento de /o/, nota-se que apenas uma ocorrência pode ser explicada pela presença de uma vogal alta na sílaba seguinte à da pretônica-alvo: [u]s.pi.tal. Da mesma forma, apesar de o fato de /o/ inicial seguido por sibilante em coda silábica mostrar-se altamente favorecedor do alçamento (PR 0.995), verifica-se, dentre as nove ocorrências, apenas esse mesmo vocábulo com estrutura silábica /oS/.

Por conseguinte, pode-se afirmar que os resultados apontam, para /o/, a preservação da vogal média-alta pretônica em contexto inicial. Os casos de alçamento variável podem ser explicados por fatores extralinguísticos e pelo modelo da difusão lexical, dada a ausência de um condicionamento fonético específico que engatilha o fenômeno. Por sua vez, a pretônica /e/ inicial apresenta um comportamento bastante divergente de /o/ em início de vocábulo no que se refere ao alçamento, sendo observados condicionadores fonéticos relacionados principalmente à presença de /N/ e /S/ em coda silábica. Destarte, configura um fenômeno neogramático (BISOL, 2009). Realizada a análise dos dados, passa-se, na seção seguinte, às considerações finais.

\section{Considerações finais}

A partir deste trabalho sobre vogais médias pretônicas iniciais na variedade do noroeste paulista, verificam-se comportamentos bastante diferenciados para /e/ e /o/ em relação ao alçamento. Para a vogal anterior, observam-se altos índices de aplicação do fenômeno, 
especialmente quando essa vogal é seguida por /S/ ou /N/ em coda silábica. Para a vogal posterior, atesta-se a manutenção da vogal média-alta, e as poucas ocorrências de alçamento parecem indicar a influência de fatores extralinguísticos, com destaque à escolaridade do informante.

De modo geral, esta pesquisa alcança resultados similares aos estudos de Battisti (1993) e de Brandão, Rocha e Santos (2012) para as variedades gaúcha e de Nova Iguaçu $(R J)$, respectivamente. Por outro lado, expõe as singularidades desse contexto, quando comparado ao alçamento das vogais médias pretônicas internas na mesma variedade (CARMO, 2013, 2014; CARMO; TENANI, 2013). Essas singularidades relacionam-se não somente às diferentes taxas de alçamento, como também ao principal processo envolvido na aplicação do fenômeno. No caso das vogais médias pretônicas mediais, as autoras destacam a harmonização vocálica. Já para as vogais médias pretônicas iniciais, constata-se, por meio deste trabalho, uma maior atuação da redução vocálica.

Finalmente, o presente artigo contribui para a caracterização das vogais no noroeste paulista, preenchendo a lacuna previamente existente de investigações acerca do alçamento de vogais médias pretônicas em início absoluto de vocábulo nessa variedade. De modo mais abrangente, contribui para o mapeamento vocálico do PB, dado o vínculo desta pesquisa ao projeto nacional PROBRAVO.

\section{REFERÊNCIAS}

ABAURRE-GNERRE, M. B. M. Processos fonológicos segmentais como índices de padrões prosódicos diversos nos estilos formal e casual do português do Brasil. Caderno de Estudos Linguísticos, Campinas, v. 2, p. 23-44, 1981.

BATTISTI, E. Elevação das vogais médias pretônicas em sílaba inicial de vocábulo na fala gaúcha. 1993. Dissertação (Mestrado em Letras) - Instituto de Letras, Universidade Federal do Rio Grande do Sul, Porto Alegre, 1993.

BISOL, L. Harmonia vocálica: uma regra variável. 1981. Tese (Doutorado em Linguística) Faculdade de Letras, Universidade Federal do Rio de Janeiro, Rio de Janeiro, 1981.

BISOL, L. A degeminação e a elisão no VARSUL. In: BISOL, L.; BRESCANCINI, C. (org.). Fonologia e variação: recortes do Português Brasileiro. Porto Alegre: EDIPUCRS, 2002. p. 231-250.

BISOL, L. O alçamento da pretônica sem motivação aparente. In: BISOL, L.; COLLISCHONN, G. (org.). Português do Sul do Brasil - variação fonológica. Porto Alegre: EDIPUCRS, 2009. p. 73-92. 
BRANDÃO, S. F.; ROCHA, F. M. V.; SANTOS, E. R. Vogais médias pretônicas em início de vocábulo na fala do Rio de Janeiro. Letras \& Letras, Uberlândia, v. 28, n. 1, p. 273-288, jan.-jun. 2012.

CÂMARA JR., J. M. Estrutura da língua portuguesa. 40. ed. Petrópolis: Vozes, 2007 [1970].

CARMO, M. C. As vogais médias pretônicas dos verbos na fala culta do interior paulista. 2009. 119 f. Dissertação (Mestrado em Estudos Linguísticos) - Instituto de Biociências, Letras e Ciências Exatas, Universidade Estadual Paulista, São José do Rio Preto, 2009.

CARMO, M. C. As vogais médias pretônicas na variedade do interior paulista. 2013. Tese (Doutorado em Estudos Linguísticos) - Instituto de Biociências, Letras e Ciências Exatas, Universidade Estadual Paulista, São José do Rio Preto, 2013.

CARMO, M. C. As vogais médias pretônicas no noroeste paulista: comparação com outras variedades do Português Brasileiro. Estudos Linguísticos, v. 43, n. 1, p. 33-47, 2014.

CARMO, M. C.; TENANI, L. E. As vogais médias pretônicas na variedade do noroeste paulista. Alfa: Revista de Linguística. v. 57, n. 2, p. 607-637, 2013.

CHAMBERS, J. K. Sociolinguistic Theory. Singapore: Wiley-Blackwell, 2009 [1995].

COELHO, I. L. et al. Para conhecer Sociolinguística. São Paulo: Contexto, 2015.

COLLISCHONN, G. A sílaba em português. In: BISOL, L. (org.). Introdução a estudos de fonologia do Português Brasileiro. 2. ed. Porto Alegre: EDIPUCRS, 1999. p. 91-119.

COLLISCHONN, G. Fonologia do português brasileiro, da sílaba à frase. Porto Alegre: Gráfica da UFRGS, 2006.

GONÇALVES, S. C. L. Banco de dados Iboruna: amostras eletrônicas do português falado no interior paulista. Disponível em: http://www.iboruna.ibilce.unesp.br/. Acesso em: 9 mai. 2013.

LABOV, W. Padrões sociolinguísticos. Tradução Marcos Bagno, Maria Marta Pereira Scherre e Caroline Rodrigues Cardoso. São Paulo: Parábola, 2008 [1972].

SELKIRK, E. The Syllable. In: HULST, H.; SMITH, N. (ed.). The Structure of Phonological Representations (Part II). Dordrecht: Foris, 1982. p. 337-383. 
SILVEIRA, A. A. M. As vogais pretônicas na fala culta do noroeste paulista. 2008. Dissertação (Mestrado em Estudos Linguísticos) - Instituto de Biociências, Letras e Ciências Exatas, Universidade Estadual Paulista, São José do Rio Preto, 2008.

TENANI, L. E. Domínios prosódicos no Português do Brasil: implicações para a prosódia e para a aplicação de processos fonológicos. 2002. Tese (Doutorado em Linguística) - Instituto de Estudos da Linguagem, Universidade Estadual de Campinas, Campinas, 2002 